\title{
Feasibility of Utilizing Recycled Aggregate Concrete for Revetment Construction of the Lower Yellow River
}

\author{
Pan Feng ${ }^{1}$, Honglei Chang ${ }^{2, *} \mathbb{D}$, Guodong $\mathrm{Xu}^{3}{ }^{3}$, Qiaoling Liu ${ }^{4}$, Zuquan Jin ${ }^{5}{ }^{(D)}$ and Jian Liu ${ }^{2, *}$ \\ 1 School of Material Science and Engineering, Southeast University, Nanjing 211189, China; \\ pan.feng@seu.edu.cn \\ 2 School of Qilu Transportation, Shandong University, Jinan 250002, China \\ 3 Jiangsu Testing Center for Quality of Construction Engineering, Nanjing 210028, China; seuxgd@126.com \\ 4 School of Civil Engineering, Shandong Jianzhu University, Jinan 250101, China; lq1263@sdjzu.edu.cn \\ 5 School of Civil Engineering, Qingdao University of Technology, Qingdao 26033, China; jinzuquan@126.com \\ * Correspondence: hlchang@sdu.edu.cn (H.C.); 1j75@sdu.edu.cn (J.L.)
}

Received: 12 November 2019; Accepted: 13 December 2019; Published: 17 December 2019

\begin{abstract}
To explore the feasibility of utilizing recycled aggregate concrete (RAC) in revetment construction of the lower Yellow River, a series of mix proportions with local recycled aggregates (RA) were designed to evaluate its mechanical properties and durability. The morphology and micro-hardness of the interface transition zone (ITZ) were also characterized to explain the performance of RAC. Based on the compressive strength data of 13 groups of mixtures, which is larger than $30 \mathrm{MPa}$, and with the RA substitution rate not less than $50 \%$, the RAC containing $50 \%$ recycled fine aggregate (RFA) (HDX50), 70\% RFA (HDX70), and 50\% recycled coarse aggregate (RCA) (HDC50) were selected. The experiment results suggest that the mechanical performance, frost resistance, and carbonation resistance of the selected RAC is generally poorer than that of natural aggregate concrete (NAC), but can meet the performance requirement of concrete for the revetment construction of the lower Yellow River. The comprehensive performance of these three mixtures ranks as: HDX50 > HDX70 > HDC50. When considering the RA substitution ratio as a priority, HDX70 would be the best choice and can be applied in the revetment engineering. A number of defects are observed on the surface of RA with old pastes attached. Furthermore, the ITZs formed around RA are loose and with low micro-hardness, which is deemed to be the dominating reasons leading to the weaker performance of RAC than that of NAC.
\end{abstract}

Keywords: revetment engineering; recycled aggregate; concrete; mechanical properties; freeze-thawing; carbonation

\section{Introduction}

The Yellow River, the second largest river in China, has nurtured generations of Chinese people, but its river flood has also caused great losses to human's lives and properties for thousands of years. In recent decades, the Yellow River conducted integrated management, and the construction of revetment was one of the most important steps [1,2] because it protected the earthy levee from the damage of water flow, waves, or ice covers. The revetment is now mainly constructed by natural stone masonry and works well. However, large natural stone exploitation has caused extensive impact on environment, and hence is restricted. Consequently, the revetment construction is being suspended or postponed. Therefore, other replacement material is urgently needed to guarantee the timely construction of the revetment.

Concrete is believed to be a promising replacement, considering that it is a cheap construction material with excellent properties, and it has been successfully used in some river management projects. 
The biggest problem is that the aggregates needed for concrete, such as gravels and river sands, are also in shortage, and their exploitation will cause damage to the environment like natural stone masonry. Replacing natural aggregates (NAs) with recycled aggregates (RAs) to produce recycled aggregate concrete (RAC) blocks provides an eco-friendly and cost-effective alternative, especially given that tons of waste concrete are produced every year in cities along the Yellow River due to the demolition of old buildings [3,4].

RAC has been studied for several decades, and many researches [5-9] focus on its mechanical properties and durability. Ravindrarajah et al. [5] conducted one of the earliest experiments with recycled fine aggregate (RFA), and the results showed that the compressive and splitting tensile strength reduced slightly and the elasticity modulus decreased by about $15 \%$ when natural fine aggregate was totally replaced by RFA. However, when the substitution rate of RFA is less than $30 \%$, several studies [10-15] found that the mechanical properties of RAC were limitedly influenced. Furthermore, Xiao et al. [16] reported a remarkable reduction in compressive strength of RAC, especially when the natural coarse aggregate (NCA) was $50 \%$ replaced by recycled coarse aggregate (RCA). Besides, Silva et al. [6] found that the elastic modulus of RAC decreased with increasing RCA. In general, the mechanical properties of RAC are worse than that of natural aggregate concrete (NAC), especially when the RA replacement is large. This could be attributed to the defects of RA, the weak interface between aggregate and paste, and the higher water absorption of the adhered mortar on RCA [6-9,17-20].

The frost resistance, carbonation resistance, chloride penetration resistance, and impermeability are often used to evaluate the durability of concrete. Generally, RAC is not recommended to use in harsh conditions [7] because of its weak frost resistance. Haitao [20] reported that the compressive strength, flexural strength, and splitting tensile strength of RAC decreased when the freezing and thawing cycles increased. Similar phenomena were reported by Salih [21], Yue [22], and Chen [23] that the relative elastic modulus decreased and the mass loss of concrete increased when exposed to freezing and thawing cycles. In addition, $\mathrm{Wu}$ [24] discovered that, with the increase of freeze-thawing cycles, both the compressive strength and modulus of RAC decreased linearly, and its compressive strength was lower than that of NAC after the same cycles. To improve the frost resistance of RAC, Salem et al. [25] infused 5\% gas content and made RAC suitable for moderately cold climates.

Similar to the mechanical properties and frost resistance, the carbonation resistance of RAC usually decreases with the increase of RA dosage [7,26,27]. Silva et al. [27] found that the carbonation depth of RAC with 100\% RCA replacement became 2.5 times larger than the reference. This value increased to 8.7 times when the aggregates were $100 \%$ replaced by RFA, probably due to the higher water absorption rate of RFA. However, according to the study of Lei [26], the carbonation depth of RAC could be lower than that of NAC under the same carbonation condition when the substitution ratio of RCA is over $70 \%$ and the adhered mortar content of RCA exceeds $40 \%$. The authors attributed these seemingly abnormal results to the higher content of adhered mortar, which actually increases the total cement content and slows down the carbonation. In summary, the impact of RA on carbonation resistance of RAC is very complicated owning to the variations in material properties.

Furthermore, according to the previous investigations [28-30], the impermeability of RAC decreased with the increase of the RA content. Additionally, the chloride penetration resistance of RAC was generally lower than that of NAC [31-33]. However, it has been found that when RAC is prepared at a low water to cement ratio (W/C), it exhibits better performance than NAC in chloride attack environments, probably because of the higher C-S-H gel content in RAC, which enhances the chloride binding capacity [34-36].

Based on the above, it can be found that there have been a number of studies about RAC, and almost all of them indicate that the properties of RAC are generally poorer than that of NAC. A few contradictory findings are mainly caused by the different material properties of RA, which can be further traced back to the sources and locations, mix proportions, impurities, such as red block residues and soil, and the service history. All the differences mentioned above make the microstructure of the 
interface transition zones (ITZ) between the RA and the new cement paste and the RA and the old mortar differ a lot and are very complicated $[37,38]$, which greatly influences the performance of RAC.

RAC has been applied to many recent projects [39,40], such as road constructions and non-load bearing structures. However, the application of RAC on revetment constructions has rarely been reported. Particularly, the revetment construction of the lower Yellow River has high requirements for the performance of RAC. On the one hand, the RAC blocks are required to have high mechanical performances (compressive strength $>30 \mathrm{MPa}$ and flexural strength $>4 \mathrm{MPa}$ ) to resist the impact load of the water stream, storm, and ice cover. On the other hand, RAC blocks need to have sound frost resistance (the temperature of the Yellow River is lower than $0{ }^{\circ} \mathrm{C}$ for about 60 days per year) to withstand the freezing and thawing cycles.

\section{Experiments}

\subsection{Raw Materials}

The raw materials used in this study consisted of cement, NA, RA, water, and water reducer. The cement was PO 42.5 (Portland Cement), produced by Shanshui Cement Co., Ltd. (Jinan, China), and its chemical composition is shown in Table 1. The natural coarse aggregates (NCAs) were gravels with good grading and the maximum size was less than $25 \mathrm{~mm}$. The natural fine aggregates (NFAs) were river sand with 3.0 fineness modulus (medium sand). The water reducer was the polycarboxylate superplasticizer produced by Qinfen Building Material Company (Jinan, China).

Table 1. The chemical composition of cement (\%).

\begin{tabular}{ccccccccc}
\hline $\mathrm{SiO}_{2}$ & $\mathrm{Al}_{2} \mathrm{O}_{3}$ & $\mathrm{Fe}_{2} \mathrm{O}_{3}$ & $\mathrm{CaO}$ & $\mathrm{MgO}$ & $\mathrm{TiO}_{2}$ & $\mathrm{Na}_{2} \mathrm{O}$ & $\mathrm{K}_{\mathbf{2}} \mathrm{O}$ & $\mathrm{SO}_{3}$ \\
\hline 21.1 & 7.81 & 2.91 & 54.4 & 3.187 & 0.425 & 0.191 & 0.399 & 2.930 \\
\hline
\end{tabular}

RA was from the derelict buildings in Jinan city, Shandong province, and had been processed by Shandong Mingran Renewable Resources Utilization Co., Ltd. The processing was mainly about removing the steel bars and most of the red bricks. The appearance of RA is shown in Figure 1. It was found that RAC was mainly made up of old paste attached to old graves and red bricks, while RAF mainly consisted of broken old pastes and red bricks. Moreover, the particle size of RCA was in the range of 5-25 mm with good grading, and that of RFA was less than $4.75 \mathrm{~mm}$ with 2.7 fineness modulus (medium sand). The properties of RA are presented in Table 2.

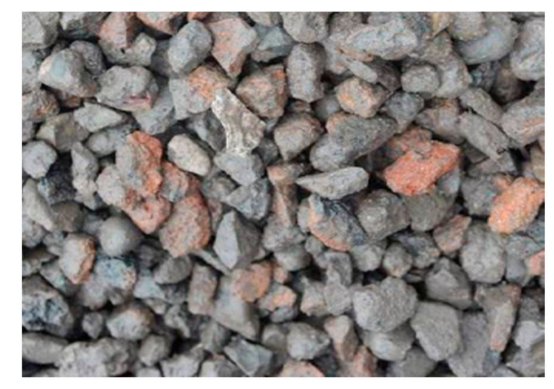

(a)

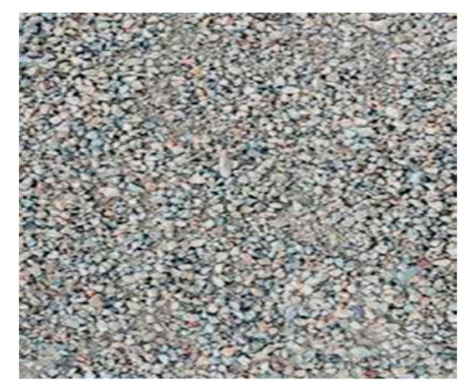

(b)

Figure 1. Macroscopic appearance of recycled aggregates: (a) Coarse aggregates (b) fine aggregates. 
Table 2. The parameters of recycled coarse and fine aggregates.

\begin{tabular}{ccccccc}
\hline Items & Clay (\%) & Brick (\%) & $\begin{array}{c}\text { Elongated and } \\
\text { Flaky Particle (\%) }\end{array}$ & $\begin{array}{c}\text { Crushing } \\
\text { Value (\%) }\end{array}$ & $\begin{array}{c}\text { Water } \\
\text { Absorption (\%) }\end{array}$ & $\begin{array}{c}\text { Apparent } \\
\text { Density }\left(\mathbf{k g} / \mathbf{m}^{\mathbf{3}}\right)\end{array}$ \\
\hline RCA & 1.1 & 0.6 & 6.50 & 17.6 & 6.40 & 2544 \\
RFA & 0.7 & 0.4 & $/$ & $/$ & 26.3 & 2562 \\
\hline
\end{tabular}

Note: RCA is recycled coarse aggregate, RFA is recycled fine aggregate.

\subsection{Concrete Mix Proportions}

Three groups of RAC were designed: single mixed with RCA, single mixed with RFA, and double mixed with RCA and RFA. Each series includes 4 mix proportions: The substitution ratio of RA being $30 \%, 50 \%, 70 \%$, and $100 \%$ of NA by mass, respectively. The label of all mixes and the detailed information are shown in Table 3.

Table 3. The mix proportions of recycled aggregate concrete (RAC).

\begin{tabular}{|c|c|c|c|c|c|c|c|c|}
\hline \multirow{2}{*}{ NO. } & \multirow{2}{*}{$\mathrm{W} / \mathrm{C}$} & \multirow{2}{*}{ Cement } & \multicolumn{2}{|c|}{ Coarse Aggregate } & \multicolumn{2}{|c|}{ Fine Aggregate } & \multirow{2}{*}{ Water } & \multirow{2}{*}{ Superplasticizer } \\
\hline & & & Natural & Recycled & Natural & Recycled & & \\
\hline $\mathrm{HO}$ & 0.39 & 330 & 1136 & 0 & 760 & 0 & 130 & 1 \\
\hline HDC30 & \multirow{4}{*}{0.39} & \multirow{4}{*}{330} & 795 & 341 & \multirow{4}{*}{760} & \multirow{4}{*}{0} & \multirow{4}{*}{130} & 1 \\
\hline HDC50 & & & 568 & 568 & & & & 1 \\
\hline HDC70 & & & 341 & 795 & & & & 1 \\
\hline HDC100 & & & 0 & 1136 & & & & 1 \\
\hline HDX30 & \multirow{4}{*}{0.39} & \multirow{4}{*}{330} & \multirow{4}{*}{1136} & \multirow{4}{*}{0} & 532 & 228 & \multirow{4}{*}{130} & 1 \\
\hline HDX50 & & & & & 380 & 380 & & 1 \\
\hline HDX70 & & & & & 228 & 532 & & 1 \\
\hline HDX100 & & & & & 0 & 760 & & 2 \\
\hline HF30 & \multirow{4}{*}{0.39} & \multirow{4}{*}{330} & 795 & 341 & 532 & 228 & \multirow{4}{*}{130} & 1 \\
\hline HF50 & & & 568 & 568 & 380 & 380 & & 2 \\
\hline HF70 & & & 341 & 795 & 228 & 532 & & 2 \\
\hline HF100 & & & 0 & 1136 & 0 & 760 & & 3 \\
\hline
\end{tabular}

Note: $\mathrm{H}$ = revetment, $\mathrm{D}=$ single mixing; $\mathrm{F}=$ double mixing; $\mathrm{C}=$ recycled coarse aggregate; $\mathrm{X}=$ recycled fine aggregate, water to cement ratio $(\mathrm{W} / \mathrm{C})$.

\subsection{Casting and Curing}

After stirring, concrete paste was poured into molds of different sizes. Specimens for compressive strength and carbonation resistance tests were cast in molds with a size of $100 \mathrm{~mm} \times 100 \mathrm{~mm} \times 100 \mathrm{~mm}$, while specimens for flexural strength and frost resistance tests were cast in molds with a size of $100 \mathrm{~mm}$ $\times 100 \mathrm{~mm} \times 400 \mathrm{~mm}$. After casting, the mold surfaces were sealed with thin film to prevent moisture evaporation. Then specimens were demolded after $24 \mathrm{~h}$ and cured at $23 \pm 1{ }^{\circ} \mathrm{C}$, at relative humidity of $95 \%$. Specimens for compressive strength were cured for 3 days, 7 days, 28 days, 56 days, and 90 days separately, and all other specimens were cured for 28 days.

Note that the slump of all mixtures in casting falls in the range of 150 180 mm. The slump of RAC is slightly lower than that of NAC with the same dosage of water reducer. Additionally, the slump of RFA concrete approximates that of RCA concrete with different RA admixtures, attributed to the fact that the water absorptivity of the former is higher, while the actual dosage of the latter is greater. The slump of concrete with mixed RFA and RFC is a little lower. Therefore, when their dosage is higher than $50 \%$, more water reducer is added to reach similar workability to that of concrete with only RFA or RFC, which aims to alleviate the impact of workability on the performance of different mixtures as much as possible. 


\subsection{Compressive Strength and Flexural Strength}

The compressive strength and flexural strength were tested abiding by the GB/T 50081-2002 standard for test method of mechanical properties on ordinary concrete [41]. As introduced in Section 2.3, specimens of size $100 \mathrm{~mm} \times 100 \mathrm{~mm} \times 100 \mathrm{~mm}$ and $100 \mathrm{~mm} \times 100 \mathrm{~mm} \times 400 \mathrm{~mm}$ were prepared for compressive strength tests and flexural strength, using $200 \mathrm{t}$ compressive strength tester and $10 \mathrm{t}$ flexural strength tester with the loading $0.5 \mathrm{MPa} / \mathrm{s}$ and $0.05 \mathrm{MPa} / \mathrm{s}$, separately. Three specimens of each mix were randomly chosen, and the average value of them was used for analysis.

\subsection{Freezing and Thawing}

According to the DG/TJ 08-2018-2007 technical code on the application of recycled aggregate concrete [42], the frost resistance requirements for RAC are presented in Table 4. The RAC investigated in this study is for revetment construction of the lower Yellow River, which belongs to the "Positions impacted by cyclic wetting-drying or water level changing", and the frost resistance grade should be over F50. Therefore, 75 freezing and thawing cycles were adopted to evaluate the frost resistance of RAC specimens.

Table 4. Frost resistance requirements for RAC under different service conditions.

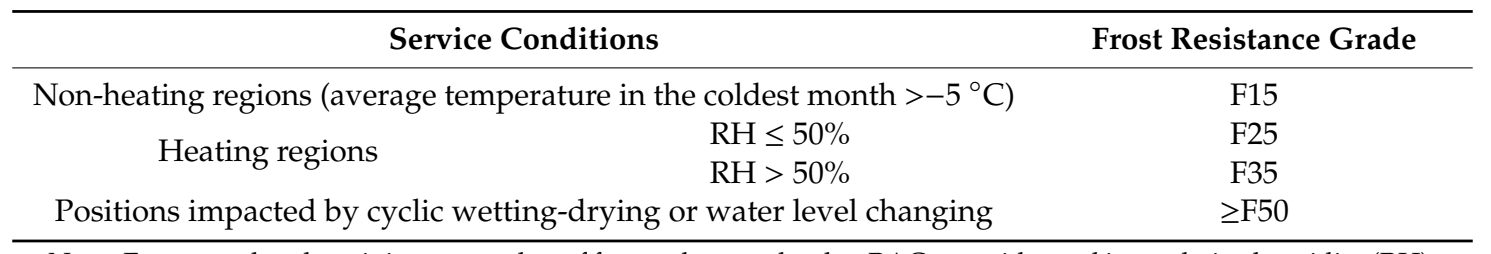

Note: Fn means that the minimum number of freeze-thaw cycles that RAC can withstand is n; relative humidity (RH).

The frost resistance test was conducted abiding by the GB/T 50082-2009 standard for test methods of long-term performance and durability of ordinary concrete [43]. Specimens with a size of $100 \mathrm{~mm} \times$ $100 \mathrm{~mm} \times 400 \mathrm{~mm}$ were used. The core temperature of specimens was kept at $(-18 \pm 2){ }^{\circ} \mathrm{C}$ and $(5 \pm$ 2) ${ }^{\circ} \mathrm{C}$ during freezing and thawing. The water surface in the container was at least $5 \mathrm{~mm}$ above the specimen surface. Relative dynamic modulus and mass loss were measured for specimens subjected to freezing and thawing for 0, 25, 50, and 75 cycles, respectively, with the use of Equations (1) and (2). The average value of three specimens was adopted. The lab photo of the frost resistance test is shown in Figure 2.

$$
P_{\mathrm{i}}=\frac{f_{n i}^{2}}{f_{o i}^{2}} \times 100
$$

where, $P_{i}$ is the relative dynamic modulus of specimens after $n$ freezing and thawing cycles; $f_{n i}$ is the dynamic modulus of specimens after $n$ freezing and thawing cycles, $\mathrm{Hz} ; f_{o i}$ is the original dynamic modulus of specimens before the test, $\mathrm{Hz}$.

$$
\Delta W_{n i}=\frac{W_{o i}-W_{n i}}{W_{o i}} \times 100
$$

where, $\Delta W_{n i}$ is the mass loss rates of specimens after $n$ freezing and thawing cycles, $\% ; W_{n i}$ is the mass of concrete after $n$ freezing and thawing cycles, $g ; W_{o i}$ is the original mass of concrete before the test, $g$. 


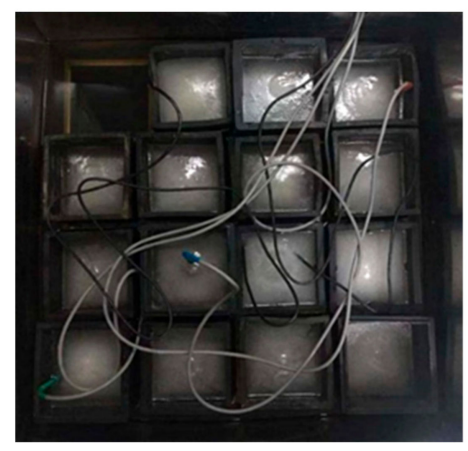

Figure 2. Freezing and thawing testing.

\subsection{Carbonation}

The carbonation resistance test was conducted abiding by the GB/T 50082-2009 standard for test methods of long-term performance and durability of ordinary concrete [43]. Cubic specimens (100 mm $\times 100 \mathrm{~mm} \times 100 \mathrm{~mm}$ ) were first dried in an oven at $60^{\circ} \mathrm{C}$ for $3 \mathrm{~d}$; then five surfaces of each specimen were sealed with paraffin. The specimens were placed in an accelerated carbonation chamber with the $\mathrm{CO}_{2}$ concentration at $(20 \pm 1) \%$, relative humidity at $(70 \pm 5) \%$, and the temperature at $(23 \pm 2){ }^{\circ} \mathrm{C}$. It should be noted that the distance between specimens should be larger than $50 \mathrm{~mm}$ to guarantee all the specimens have the same boundary conditions. The lab photo of the carbonation resistance test is presented in Figure 3. The carbonation depths were measured after 3 days, 7 days, 14 days, and 28 days of exposure, based on which carbonation rates were calculated.

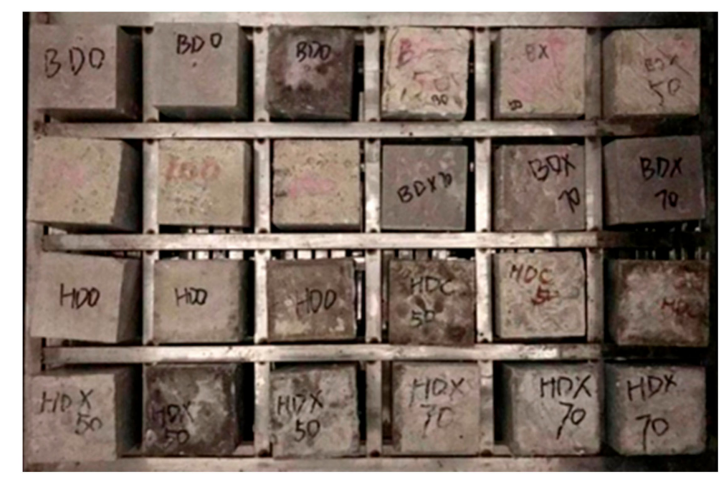

Figure 3. Carbonation testing.

The carbonation depth was tested with the method below. We sprayed phenolphthalein of $1 \%$ concentration on the split surface. Due to the alkaline solution of concrete before carbonation, the uncarbonated area turned to purple, whereas the carbonated area stayed unchanged. We marked 12 equally spaced test points along the boundary between the purple area and unchanged color area and measured the distance between each test point and the end surface of the unchanged color area. The carbonation depth was obtained by averaging the 12 measured distances. The carbonation time and depth was reported to follow the empirical relation described in Equation (3), by which the carbonation rate $k$ can be calculated.

$$
x=k \sqrt{t}
$$

where, $x$ is the carbonation depth, $\mathrm{mm} ; k$ is the carbonation rate; $t$ is the carbonation time, $\mathrm{d}$.

\subsection{Morphology}

Cubic samples with side lengths smaller than $10 \mathrm{~mm}$ were cut out from specimens exposed to different conditions with caution to make sure that at least one of the cutting faces contained both aggregates and slurry. These cubic samples were dried at $45^{\circ} \mathrm{C}$ in a vacuum drying oven for 7 days. The 
macro-appearance of aggregates and interface were observed with an industrial electronic microscope at magnification of 50 100 times. The microscopic morphology of ITZ was observed by a scanning electronic microscope (Quanta 250) at an accelerating voltage of $20 \mathrm{kV}$ and current of $20 \mathrm{~mA}$.

\subsection{Micro-Hardness}

The samples for micro-hardness measurement were prepared in the same way as mentioned in Section 2.7. After drying, these samples were impregnated with epoxy resin for $48 \mathrm{~h}$. The surface of each sample was then polished to easily identify the diamond-shaped indentation. The micro-hardness of the aggregate, ITZ, and matrix zone in both NAC and RAC were then determined by a Vickers indenter. Specifically, the target regions were determined first, then indented within the target regions by applying the load to obtain micro-hardness [44].

\section{Results and Discussion}

\subsection{Mechanical Properties}

\section{(1) Compressive Strength}

Figure 4 shows the impact of curing time on the compressive strength of RAC. One representative mixture of each RAC series was chosen for analysis: HDX50, HDC50, and HF50. It can be observed that the compressive strength of all concrete increased rapidly before 28 days, slowed down afterwards, and stabilized after 56 days. Additionally, the compressive strength of 28 days of all the specimens reached more than $90 \%$ of that of 90 days. Moreover, it can also be found that, consistent with the findings of many previous researches [10-14], the incorporation of RA decreased the compressive strength of concrete. Furthermore, the compressive strength reduction of concrete mixed with single RCA was greater than that mixed with single RFA. Furthermore, concrete with both RCA and RFA had the lowest compressive strength, particularly after 10 days of hydration.

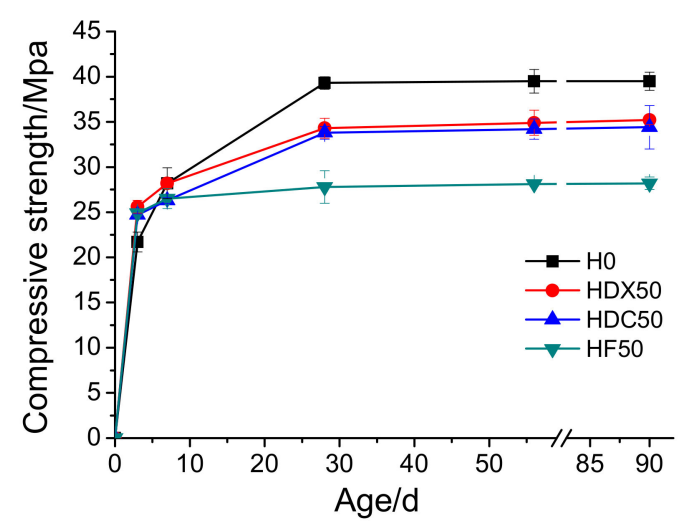

Figure 4. Influence of curing time on the compressive strength of RAC.

Figure 5 presents the compressive strength of RAC with different incorporation of RA at 28 days. It can be observed that the compressive strength of all RAC, either containing only RCA or RFA, or both RCA and RFA, gradually decreased with the increase of RA replacement at 28 days. Compared with natural concrete, RAC with both RCA and RFA had the most significant decrease in compressive strength, then RAC with single RCA, and RAC with single RFA being the least. Though the replacement percentage of the recycle aggregates was the same, the mass incorporated was different. The mass of the recycle aggregates with double replacement of RCA and RFA was the highest, then RCA, and RFA was the least. Since RA has inherent defects, such as numerous micro-cracks, large porosity, and low strength $[31,32,37,38]$, the increase of its content will introduce more flaws into concrete, leading to the rise of fragility and more severe degradation of mechanical performances. 


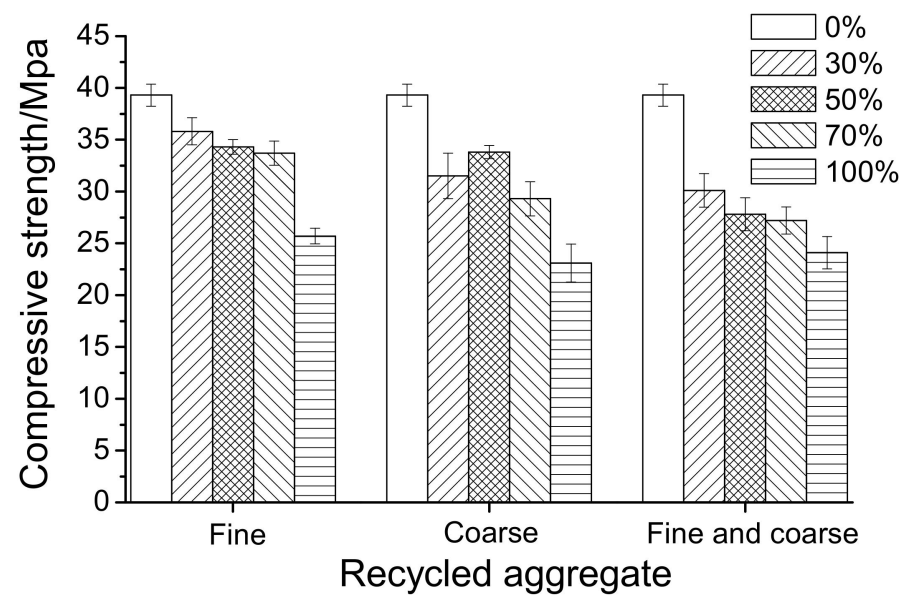

Figure 5. The 28-day compressive strength of RAC with different dosages of recycled aggregates (RA).

Moreover, it can be seen from Figure 5 that when the RFA dosage was lower than $70 \%$, the compressive strength of specimens was higher than $32.5 \mathrm{MPa}$ and the drop degree was within $15 \%$, which was superior to that of RFA concrete in other studies $[9,11,14]$. Furthermore, the compressive strength reduced to less than $30 \mathrm{MPa}$ when the dosage of RCA, mixed RCA and RFA, reached 70\%, which is significant and coincides with the findings in other studies $[7,8,11]$. It can also be observed from Figure 5 that the compressive strength of HDC50 did not conform with the regular law of compressive strength, changing with RCA content. This can be attributed to the variations in the composition of RA. The abnormity was acceptable considering the test uncertainties.

\section{(2) Flexural Strength}

Figure 6 shows the flexural strength of RAC at 28 days. It can be seen that the incorporation of RCA weakened the flexural strength of concrete, while the flexural strength of the two RFA mix proportions decreased slightly. The breaking strength of these mixtures was within 3.5 4.5 MPa, which conforms to the previous studies [6-8].

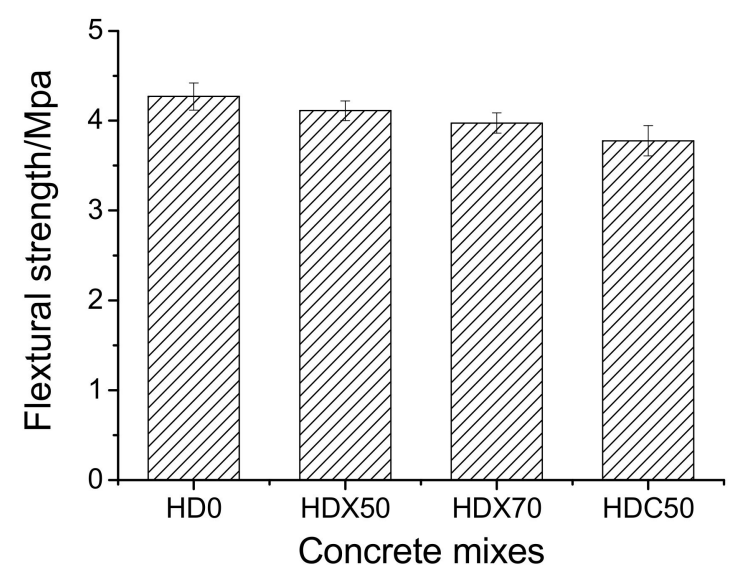

Figure 6. Flexural strength of recycled aggregate concrete at age of 28 days.

Figure 7 shows the fracture surfaces of RAC specimens. It can be observed that the fractures were mainly caused by three aspects: the interface between RA and paste, the fracture of RA, and the fracture of red brick. They were the major reasons responsible for the poor mechanical performance of RAC. 


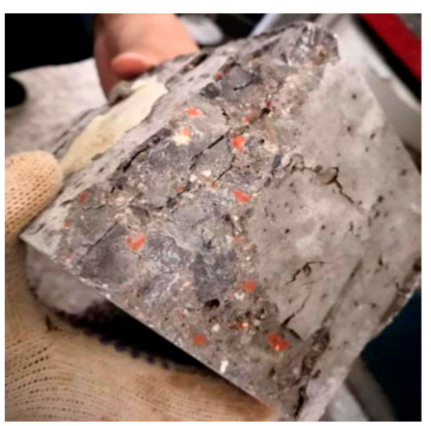

(a)

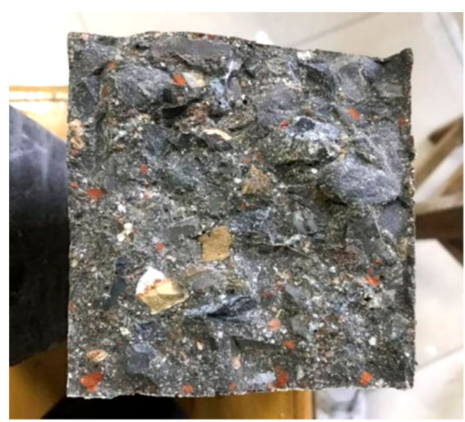

(b)

Figure 7. The morphology of fracture surface HDC50: (a) after the compression test and (b) after the flexural test.

ITZ is the weak region in either NAC or RAC, which is especially worse for RAC because the interface is usually attached with old slurry (see Figure 8). Figures 9 and 10 show the ITZ of NAC and RAC, respectively. It is clear that the ITZ of NAC was denser with no visible cracks or voids; however, there were several cracks between the RA and slurry, which made the ITZ in RAC loose and fragile. Therefore, it can be inferred that that the ITZ was the main reason for the bearing capacity decrease of RAC. This is probably due to that fact that the mass of RCA was higher and the area of ITZ was greater $[37,38]$ and the strength of concrete with RCA was lower than that with RFA, as shown in Figures 5 and 6. Moreover, the slightest strength decline of specimens mixed with only RFA can be ascribed to the RAF itself. RAF mainly consists of broken old pastes and red bricks, and after years of exposure, RFA becomes porous, resulting in high water absorptivity (see Table 2). As a result, cement particles can fill in the pores of RFA and densify the matrix. On the other hand, the water absorbed by RFA in casting can play the role of internal curing [21]. Therefore, the strength of specimens mixed with single RFA was higher.

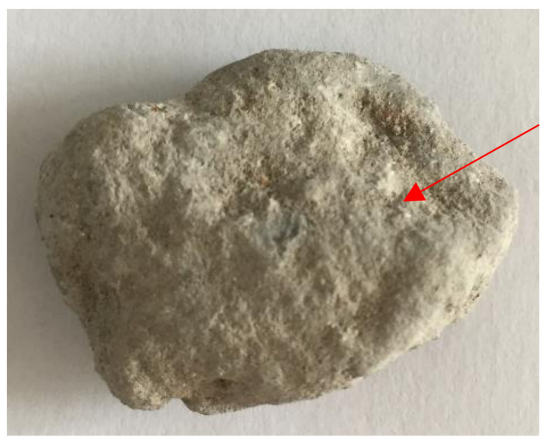

(a)

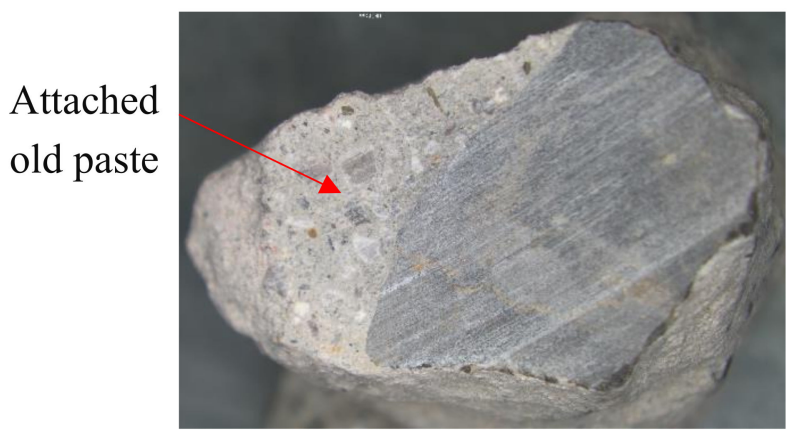

(b)

Figure 8. The recycled coarse aggregate attached with old paste: (a) appearance; (b) cross section.

As for the inherent defects of RA, Figure 11 provides the macro-appearance of NA and RA for comparison. It can be observed that NA has dense and hard texture (Figure 11a) with no visible cracks, whereas RA is porous and loose (Figure 11b) with a number of micro-cracks (Figure 10a). Therefore, the RA breaks easily under force, which decreases the mechanical performances of concrete. Furthermore, the existence of red brick particles also has a negative impact on the mechanical performances of concrete. As shown in Figure 12, red brick is porous and has low strength by itself, and its binding with paste is also weak. 


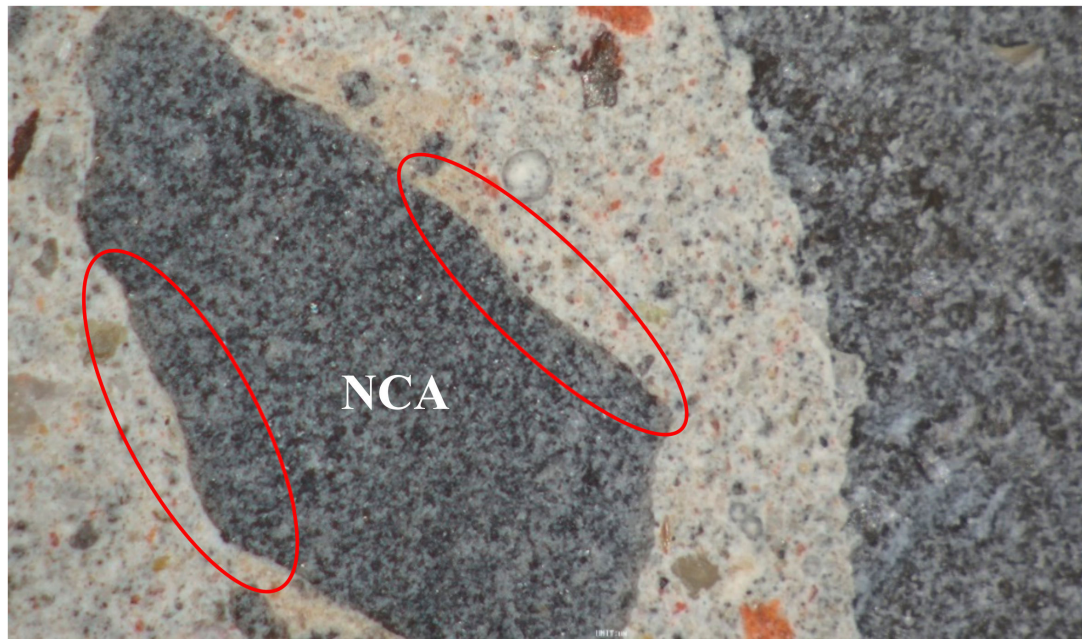

(a)

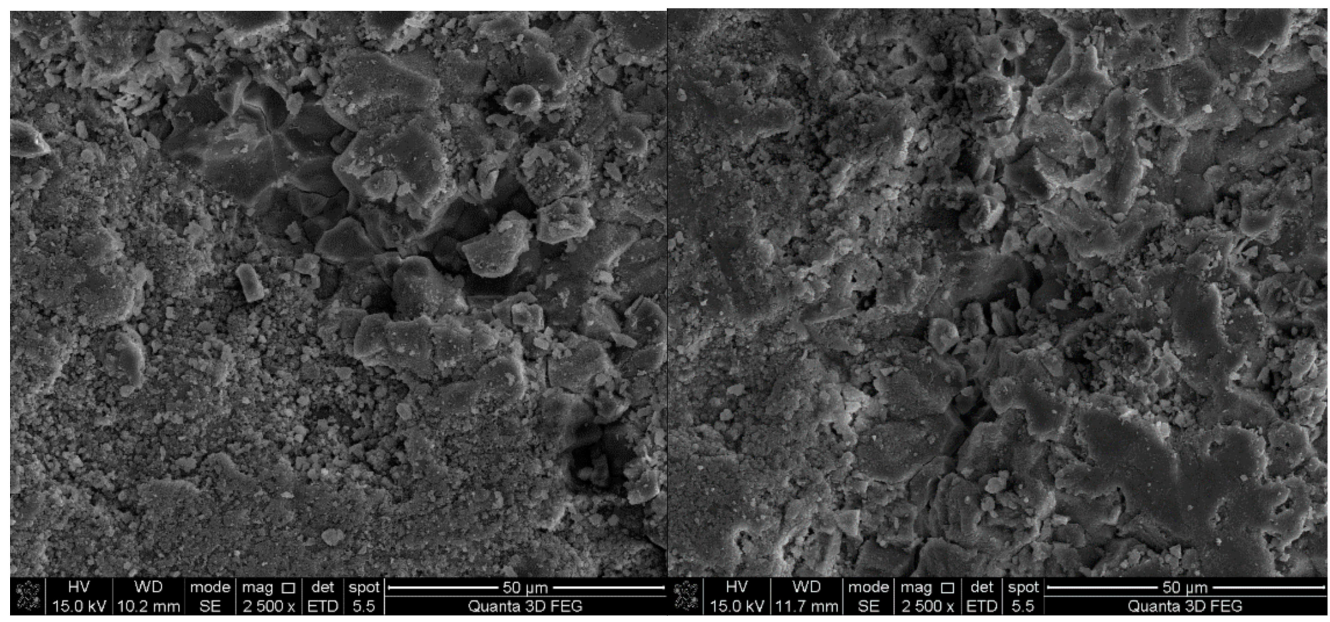

(b)

Figure 9. Interface transition zone (ITZ) of natural aggregate concrete (H0): (a) mesoscopic morphology; (b) microscopic morphology.

Figure 13 presents the Vickers hardness of the matrix zone and ITZ around NCA and RCA in H0 and HDC50. The hardness curve of NCA includes three parts: the coarse aggregate, new ITZ, and new matrix zone, while that of RCA includes five parts: the coarse aggregate, old ITZ, old matrix zone, new ITZ, and new matrix zone. It can be found that the hardness of ITZ was the lowest, then that of the matrix zone, with the hardness of aggregate being the highest, which further demonstrates that ITZ was the weakest region of concrete. Moreover, the hardness of the new matrix zone in RAC was close to that of NAC, and that of new ITZ in RAC was a little smaller than that in NAC. Hence, compared with NAC, the poorer performances of RAC should not be ascribed to the new ITZ and the new matrix zone. Furthermore, it can be seen that the hardness of the old ITZ was the lowest, and the hardness of the old matrix zone was obviously lower than that of new matrix zone in NAC at the same distance from the aggregate. The range of the old matrix zone was wide (about $420 \mu \mathrm{m}$ from the aggregate for the tested sample), owing to the RCA adopted. Therefore, it can be concluded that the poor performances of RAC was mainly related to the weakness of the old ITZ and the old matrix zone. 


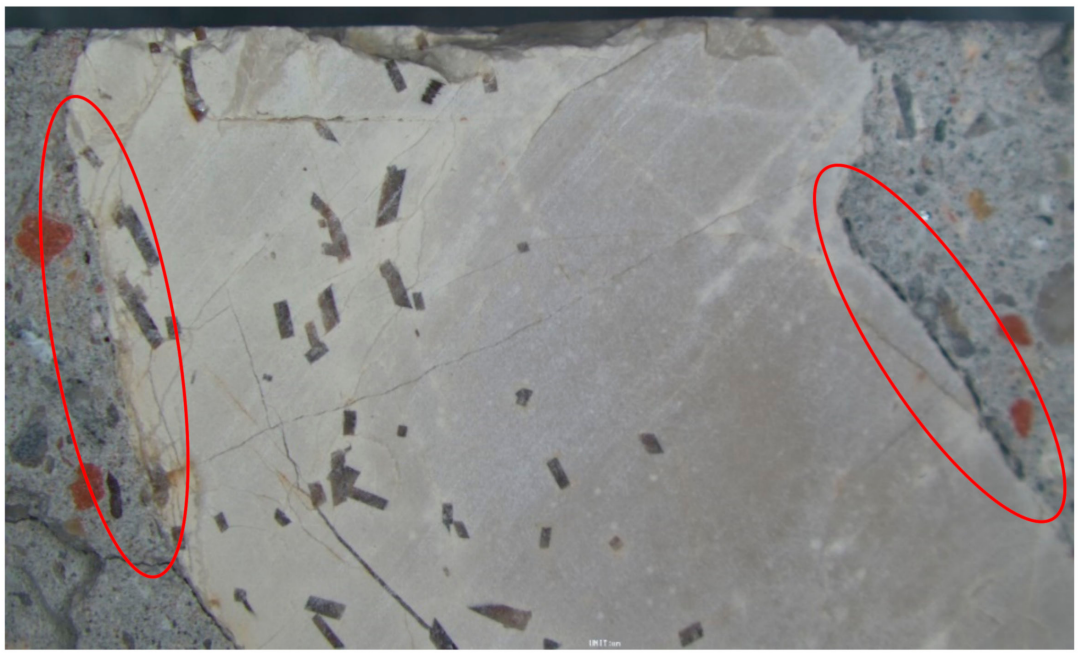

(a)

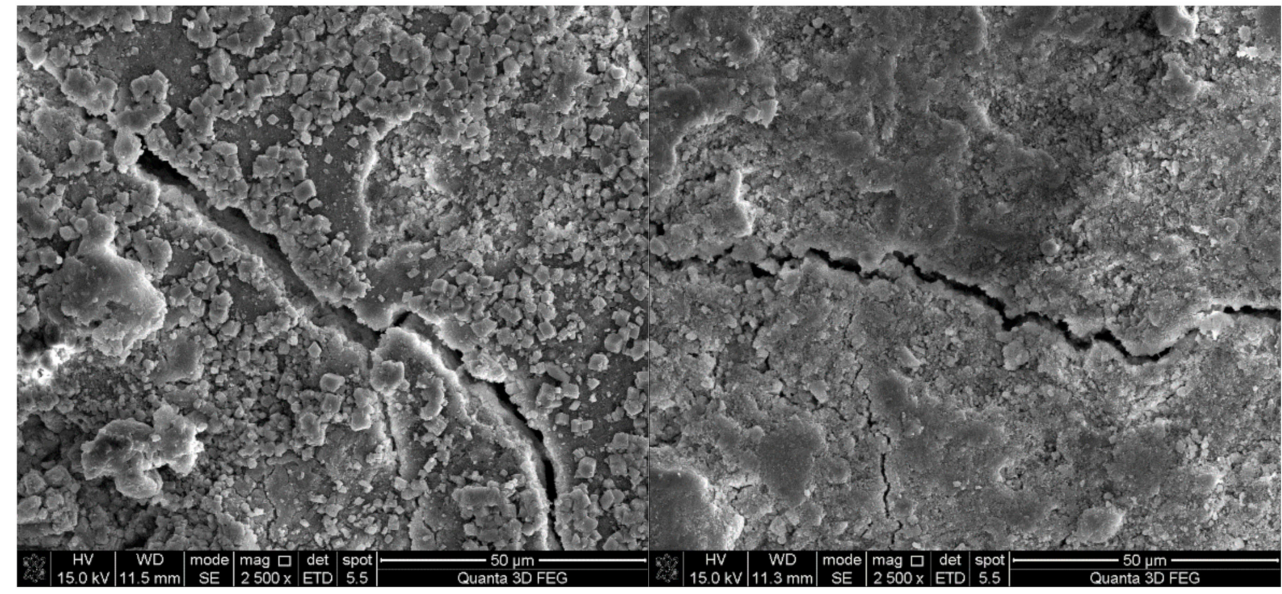

(b)

Figure 10. ITZ of recycled aggregate concrete (HDC50): (a) meso-morphology (b) micro-morphology.

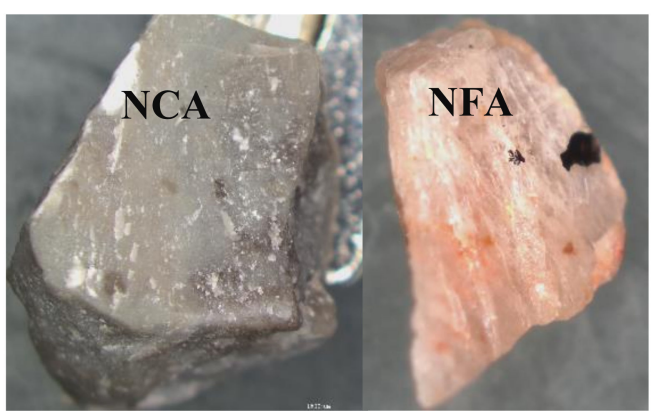

(a)

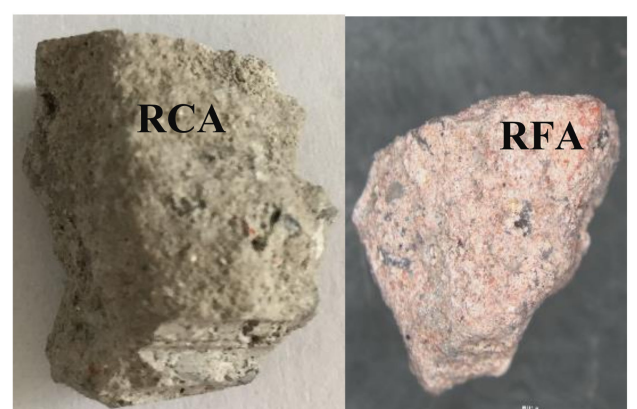

(b)

Figure 11. The macro-morphology of natural aggregates and recycled aggregates: (a) natural aggregates; (b) recycled aggregates. 


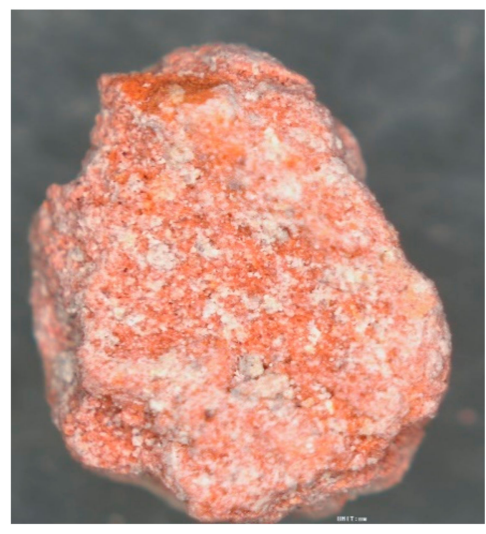

(a)

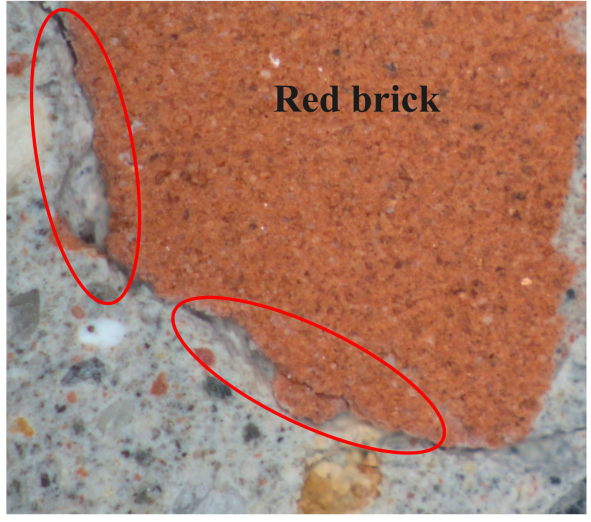

(b)

Figure 12. The macro-morphology of (a) red block particle and (b) meso-morphology of ITZ between the red block particle and paste in RAC.

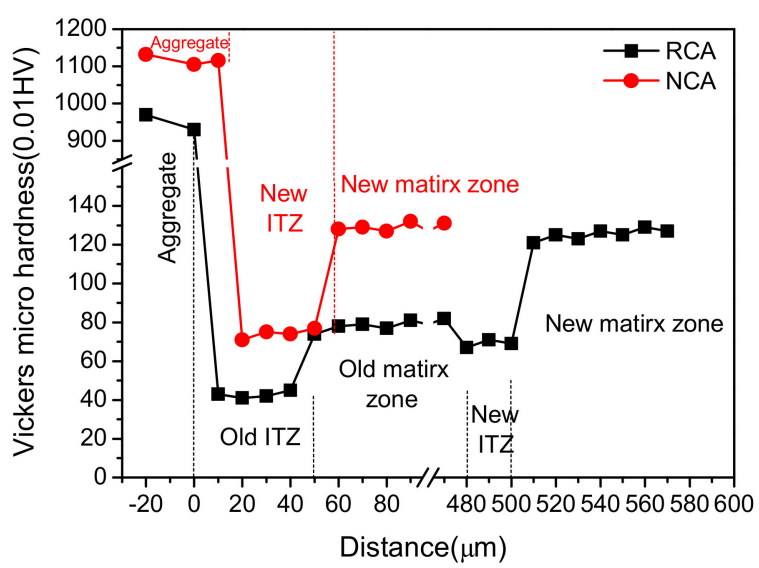

Figure 13. Micro-hardness distribution at the ITZ and matrix zone around recycled coarse aggregate (RCA) and natural coarse aggregate (NCA) in concrete.

\subsection{Frost Resistance}

\section{(1) Process and Characterization of Damage}

The appearance changes of RAC and NAC are basically the same with the increase of freezing and thawing cycles. After 25 cycles, the appearance of specimens generally remains intact, and only a small part of RAC specimens have a few edge damages and a small number of voids. After 50 cycles, numerous voids started to appear on the concrete surface, presenting the onset of a pitted surface. The appearance of $\mathrm{H} 0$ and HDX50 remained roughly intact, while only a few voids appeared, whereas the surface of HDC50 and HDX70 had a number of voids, and some of them were even connected, leading to a partial pitted surface. After 75 cycles, a pitted surface appeared on the surface of all concrete specimens, and the appearance damage of HDC50 and HDX70 was more severe with large-scale paste spalling. The detailed damage information of the four mix-proportion concrete specimens is presented in Table 5. It can be found that RAC was more severely damaged than NAC, which resulted from the defects of RA itself. Moreover, the damage of RCA concrete was worse than that of RFA concrete. On the one hand, the actual dosage of RCA was greater and there were more defects; on the other hand, the water absorbed by RFA played the role of inner curing and densifying the matrix. 
Table 5. Surface morphology of concrete specimens after different freeze-thaw cycles.

\begin{tabular}{cccc}
\hline \multirow{2}{*}{ NO. } & \multicolumn{3}{c}{ Cycles } \\
\cline { 2 - 4 } & $\mathbf{2 5}$ & $\mathbf{5 0}$ & $\mathbf{7 5}$ \\
\hline H0 & Intact & Small number of holes & $\begin{array}{c}\text { Large number of holes } \\
\text { LDX50 }\end{array}$ \\
Intact & Small number of holes & $\begin{array}{c}\text { pumber of holes; slight } \\
\text { pitted surface }\end{array}$ \\
HDX70 & Roughly intact & $\begin{array}{c}\text { Small number of holes; } \\
\text { slight pitted surface }\end{array}$ & Pitted surface; slight paste spalling \\
HDC50 & $\begin{array}{c}\text { Slight damage in corners; } \\
\text { Small number of holes }\end{array}$ & $\begin{array}{c}\text { Large number of holes; } \\
\text { pitted surface }\end{array}$ & Pitted surface; paste spalling \\
\hline
\end{tabular}

\section{(2) Mass Loss}

Figure 14 shows the mass loss rate of concrete as a function of the freezing and thawing cycles. It can be observed that the mass loss of H0, HDX50, and HDX70 presented a tendency of first decreasing, then increasing with continuous freeze-thawing cycles, which is consistent with the observation of some other researches [45]. It was probably caused by the fact that at the early stage of freezing and thawing, the paste spalling of specimens was slight and the pores in concrete could adsorb a certain amount of water from the external environment, compensating the mass loss to some degree. Especially for the specimens blended with RFA, RFA possessed higher water absorptivity, which could compensate for more mass loss. Therefore, the mass increase of HDX70 in the early stage was the most significant. At the late stage of freezing and thawing, concrete damage was then exacerbated with a large amount of paste or aggregate sapling, leading to the increase of mass loss. As is clearly presented in Figure 14, the mass loss of the three RAC concrete started to take off after 50 freezing and thawing cycles; and at 75 cycles, the mass loss of HDX50 and HDX70 gradually surpassed that of H0. However, the mass loss of HDC50 did not have a decrease phase, and it was probably because HDC50 started paste spalling at 25 freezing and thawing cycles (see Table 5), and hence the mass loss tested after different cycles gradually increased and reached $1.1 \%$ at 75 cycles. Consequently, in terms of mass loss within 75 cycles, the frost resistance of RAC with RCA was much worse than that of RAC with RFA, whose frost resistance was only slightly weaker than that of NAC.

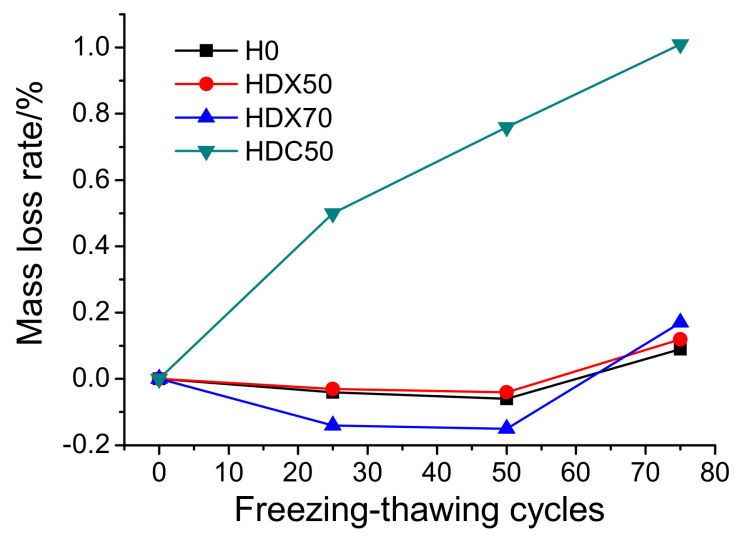

Figure 14. Mass loss rate of concrete specimens after exposed to different freeze-thawing cycles.

\section{(3) Relative Elasticity Modulus}

Figure 15 presents the relative elasticity modulus change of specimens with freeze-thawing cycles. It is clear that with the increase of freeze-thawing cycles, the relative elasticity modulus of all specimens deceased gradually. Compared with NAC (H0), the relative elasticity modulus of HDX50 and HDX70 were constantly higher, suggesting that RFA promoted the elasticity modulus and thus the frost 
resistance of concrete. According to previous research [46,47], RAF made up of broken old pastes and red brick particles contains many pores that can provide more space to alleviate the expansion stress during the frost heaving process, and thus has limited negative impact on the relative elasticity modulus of RAC. However, the relative elasticity modulus of HDC50 is significantly lower than that of other mix proportions, and the maximum elasticity modulus loss can reach $8.9 \%$, which means the frost resistance is poorer.

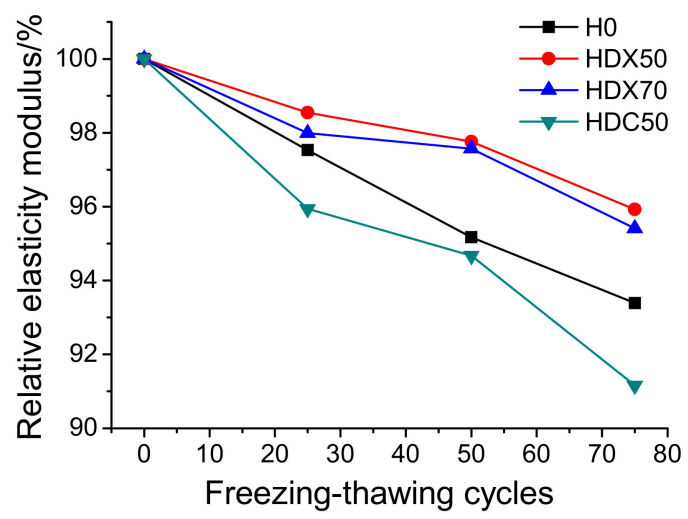

Figure 15. Relative elasticity modulus of concrete specimens after exposed to different freeze-thawing cycles.

Combining the experiment results of appearance, mass loss, and relative elasticity modulus of specimens, it can be found out that the frost resistance of RAC with RFA (HDX50/HDX70) was not necessarily worse than that of NAC, and its elasticity modulus was even higher. However, the frost resistance of RAC with RCA was significantly poorer than that of NAC. RA itself and ITZ were probably the major factors affecting the frost resistance of RAC.

It can be observed from Figure 11 that RFA had many pores that could alleviate expansion stress. In Figure 10, it is clear that RCA had many fissures that broke easily during frost heaving, leading to the degradation of all the performances of specimens after freeze-thawing cycles. Moreover, Figure 16 shows the ITZ of H0, HDX50, and HDC50 after 50 cycles. It can be observed that the ITZ of HDC50 had more defects than that of $\mathrm{H} 0$ and HDX50, which made it more fragile. Therefore, the frost resistance of HDC50 was the worst since it had more inherent defects and no alleviation capability and inner curing effect like RFA. In addition, comparing the ITZ of NAC and RAC before (see Figures $9 \mathrm{~b}$ and $10 \mathrm{~b}$ ) and after (see Figure 16) subjected to freezing and thawing, it can be found that both the ITZ of NAC and RAC had more defects after freeze-thawing, which was one of the major reasons for the degradation of the concrete.

Based on the above, it can be drawn that the frost resistance of RAC with RFA (HDX50/HDX70) was slightly weaker than that of NAC, while that of RAC with RCA was significantly worse than that of NAC. This is consistent with the findings of Salih et al. [21-23], who showed that the relative elastic modulus decreased and the mass loss of concrete increased when exposed to freezing and thawing attack. Moreover, the maximum mass loss and maximum elasticity modulus loss of the three mix-proportion RAC were $1.1 \%$ and $8.9 \%$, separately, which met the frost-resistance requirement of the revetment construction of the lower Yellow River (mass loss being no more than $5 \%$ and relative elasticity modulus being no less than $60 \%$ [42]). 


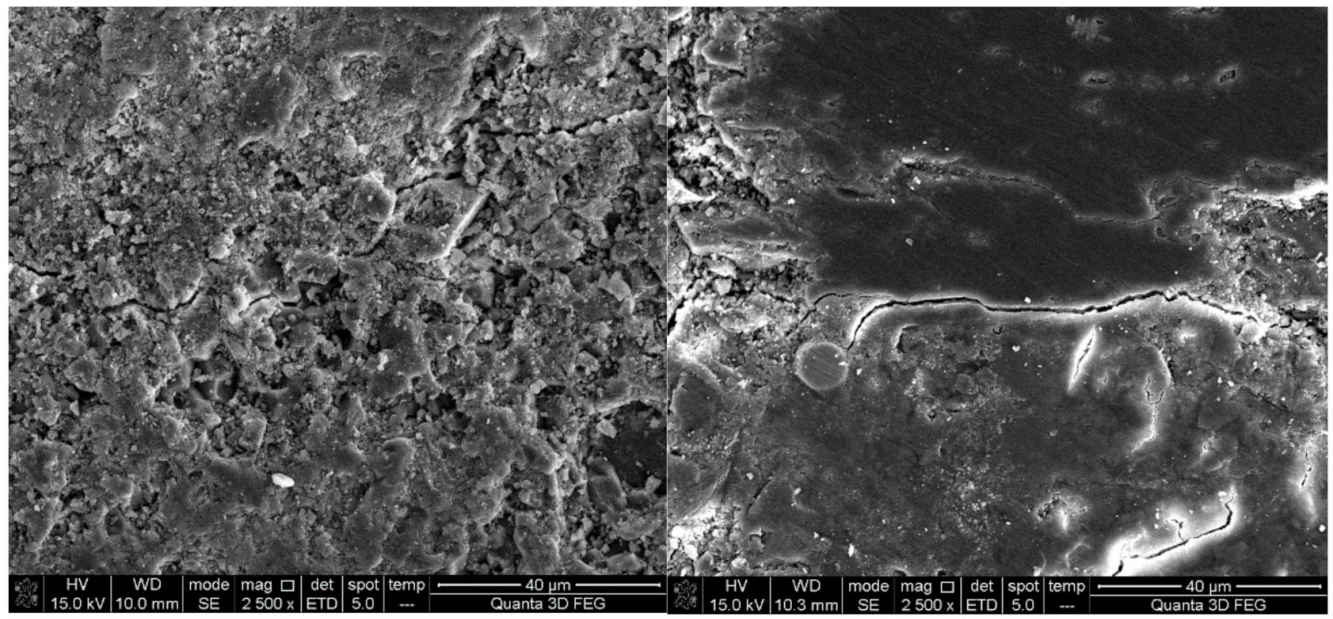

(a)

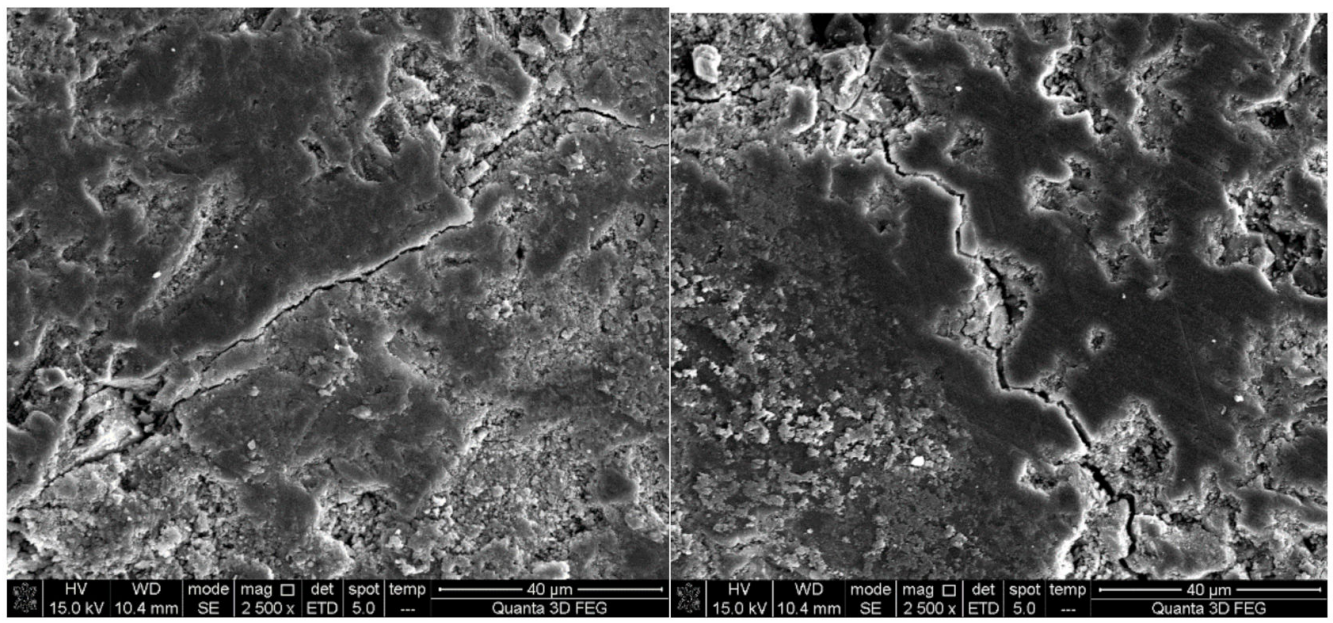

(b)

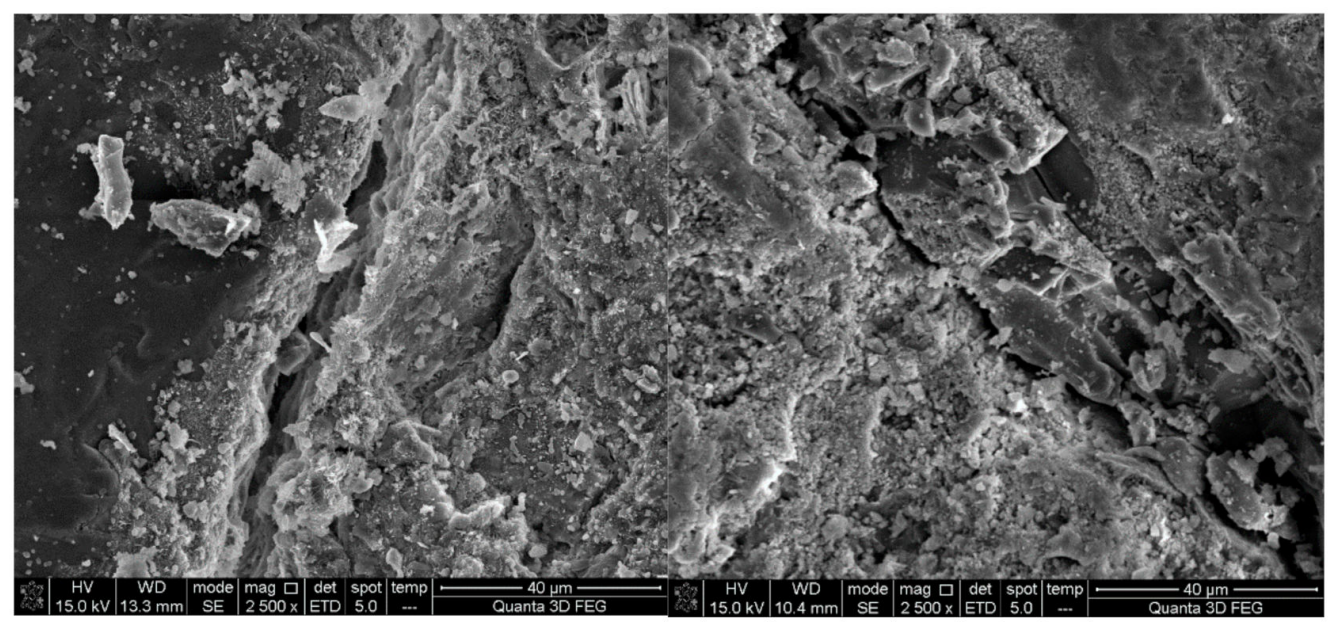

(c)

Figure 16. ITZ in H0, HDX50, and HDC50, separately, after freezing and thawing for 50 cycles: (a) H0; (b) HDX50; (c) HDC50. 


\subsection{Carbonation Resistance}

(1) Carbonation Depth

The development of carbonation depth of specimens is shown in Figure 17. It can be observed that the carbonation depth of all specimens increased with exposure time. The carbonation depth of RAC was higher than that of NAC, which can be attributed to the larger number of channels for $\mathrm{CO}_{2}$ infiltration provided by the micro-cracks and large porosity of RA. The carbonation depth of HDC50 with RCA was the highest, reaching $12.4 \mathrm{~mm}$ at 28 days, and that of $\mathrm{H} 0$ at 28 days was $7.2 \mathrm{~mm}$, the former of which was 1.7 times higher than the latter, and lower than that the result (2.5 times) of Silva et al. [27]. This demonstrates that RAC in this study had a better carbonation resistance. This is closely related to the actual RA content of RAC; the higher the actual RA content, the more channels for $\mathrm{CO}_{2}$ infiltration, leading to a more severe carbonation degree. Moreover, since specimens mixed with RFA possess certain inner curing capacities, the hydration degree was more adequate compared with that of specimens mixed with RCA, and the matrix of RFA was denser, which made $\mathrm{CO}_{2}$ infiltration harder. In addition, RFA contained more pastes, which can consume more $\mathrm{CO}_{2}$ compared with RCA. These two factors lead to the result that the carbonation depth of RFA concrete was lower than that of RCA concrete.

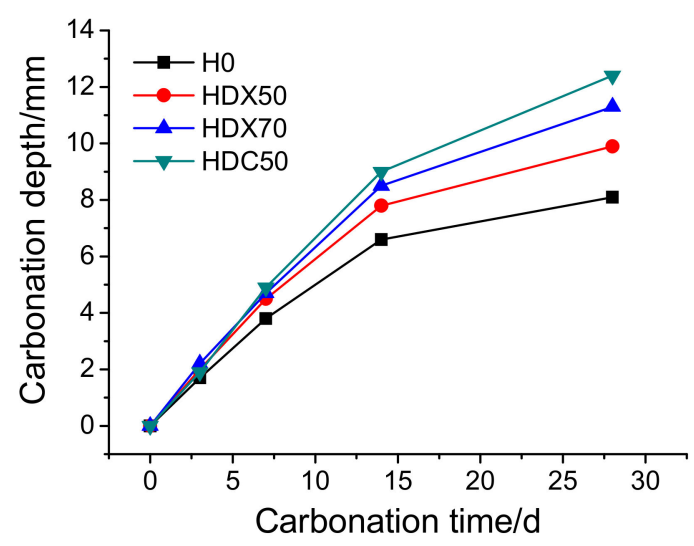

Figure 17. Carbonation depth of concrete specimens at different carbonation time.

\section{(2) Carbonation Rate}

Figure 18 presents the carbonation rate of specimens at different carbonation times. It can be found that the carbonation rate of specimens first increased rapidly, then stabilized and decreased slightly. During carbonation, the products insoluble in water gradually formed and filled in the pores in concrete and densifies its microstructure, which cut off the channels for $\mathrm{CO}_{2}$ infiltration, mitigating the following carbonation reaction, and thus slowed down the carbonation rate. As is shown in Figure 19, the micro-cracks and voids around ITZ were filled in gradually after carbonation, blocking the further infiltration of $\mathrm{CO}_{2}$. Moreover, the Vickers hardness of the ITZ and matrix zone around RA in HDC50 after carbonation is shown in Figure 20. It can be observed that the Vickers hardness of the old ITZ, old matrix zone, new ITZ, and new matrix zone after carbonation all increased significantly, suggesting that the ITZ became stiffer and carbonation improved the performance of RAC. Furthermore, with the distance to RA surface expanding, the increase of Vickers hardness multiplied gradually, revealing that the closer to RA surface, the harder the $\mathrm{CO}_{2}$ infiltration, and the weaker the carbonation degree. In addition, the carbonation rate of RAC was significantly higher than that of NAC, with HDC50 being the fastest, followed by HDX70 and HDX50, successively. 


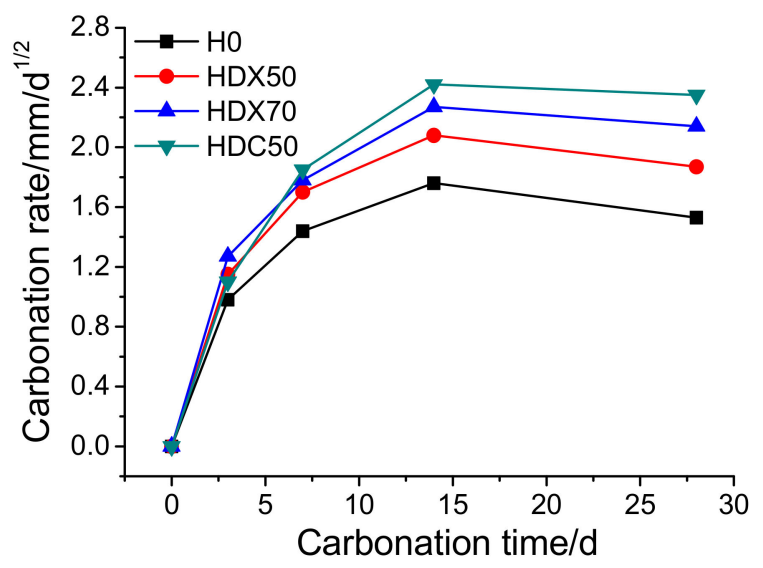

Figure 18. Carbonation rate of concrete specimens at different carbonation times.

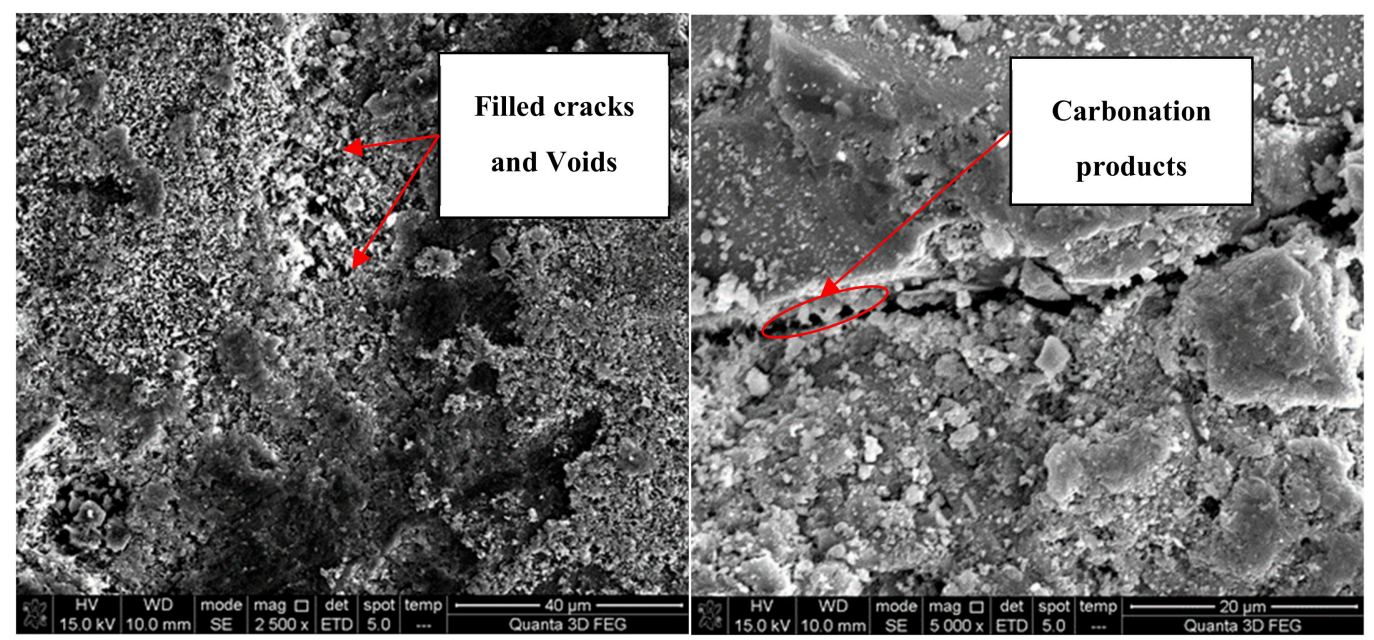

Figure 19. ITZ and micro-morphology of old paste around RCA in RAC (HDC50) after carbonation for 14 days.

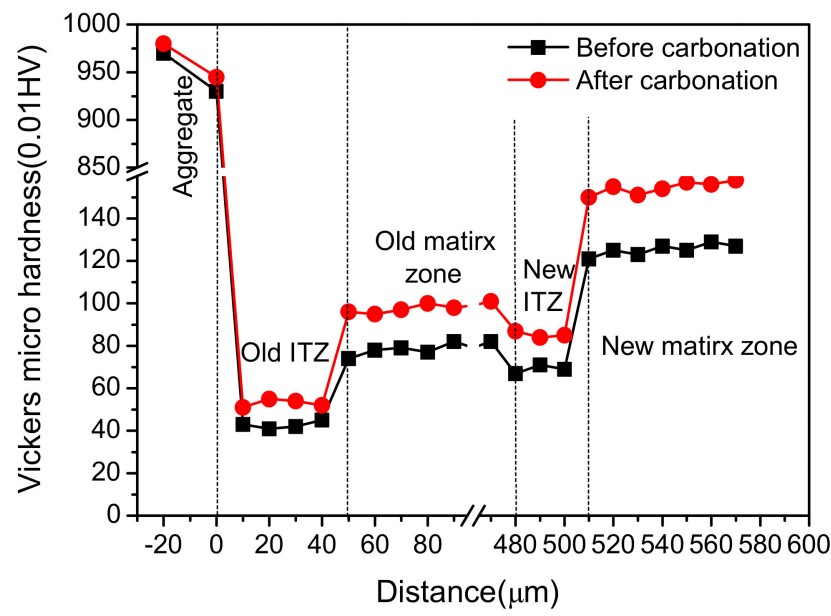

Figure 20. Micro-hardness distribution at the new and old ITZ in RAC before and after carbonation.

According to the above analysis, it can be summarized that the carbonation resistance of RAC was weaker than that of NAC. However, the carbonation depth of RAC specimens at 28 was smaller than $20 \mathrm{~mm}$, which fully met the carbonation-resistance requirement for the revetment construction 
of the lower Yellow River [42]. Additionally, the mix proportion HDX50 of RAC possessed the best carbonation resistance.

Above all, the chosen mix proportions (HDX50, HDX70, and HDC50) of RAC successfully met the performance requirement of concrete for the revetment construction of the lower Yellow River, in terms of compressive strength, flexural strength, frost resistance, and carbonation resistance. Therefore, the chosen RAC can be applied to the actual revetment engineering of the Yellow river. After analyzing and combining all the experiment results, the engineering application performance of the three mix proportions is ranked as: HDX50 > HDX70 > HDC50. If the engineering application performance and economic performance of material are considered, RAC HDX70 is the best and is recommended to be used in the actual revetment engineering of the lower Yellow River. Moreover, the RAC designed in this study with local raw material possesses superior mechanical properties and durability, which are as good as those in other studies. Therefore, it can be wildly applied, except for the bank revetment engineering of the Yellow River.

\section{Conclusions}

(1) Based on the compressive strength data at 28 days, the RAC of the mix proportions HDX50, HDX70, and HDC50 were selected for compressive strength over $30 \mathrm{Mpa}$ and a RA substitution rate no less than $50 \%$.

(2) Considering the combination of the appearance, mass loss, and relative elasticity modulus situations of specimens after freeze-thawing cycles, HDX50 possessed the best frost resistance performance, followed by HDX70 and HDC50, successively. Improvement on the relative elasticity modulus of HDX50/HDX70 was observed, compared to NAC.

(3) In view of the carbonation depth and rate of RAC, the carbonation resistance of HDX50 was the best, followed by HDX70 and HDC50. Moreover, carbonation could densify the ITZ of RAC and increase its micro-hardness.

(4) RA attached with old pastes had lots of micro-cracks and voids, and the ITZ formed around RA were loose and with low micro-hardness, which were deemed to be the dominating reasons leading to the poorer performance of RAC than that of NAC. In addition, RFA concrete had better performance than RFC concrete, since RFA possessed certain inner curing capacities.

(5) The selected HDX50, HDX70, and HDC50 meet the performance requirement of concrete for the revetment construction of the lower Yellow River in terms of mechanical and durability performance. Combing performance and RA utilization rate, HDX70 ranks first and is recommended to be used in actual revetment engineering.

Author Contributions: Conceptualization, P.F., and H.C.; Methodology, G.X., Q.L.; Software, G.X.; H.C., P.F., and J.L.; Formal Analysis, G.X.; Investigation, H.C.; Resources, J.L.; Data Curation, P.F.; Writing-Original Draft Preparation, P.F.; Writing-Review \& Editing, H.C., Z.J.; Visualization, H.C.; Supervision, Q.L., Z.J.; Project Administration, J.L.; Funding Acquisition, H.C., J.L.

Funding: Authors appreciate the financial support from the National Natural Science Foundation of China, under the contract No. 51908327 and 51608311, the Natural Science Foundation of Shandong Province, under the contract No. ZR2019QEE017, and the Fundamental Research Funds of Shandong University, under the contract No. 31560078614117.

Conflicts of Interest: The authors declare no conflict of interest.

\section{References}

1. Guo, S. A Summary of Studies on the Strategy of Governing the Yellow River in Contemporary China. J. Zhejiang Univ. Wat. Res Electr. Pow. 2019, 31, 1-4.

2. Wan, Q.; Zhang, J.; Li, J. Model test study on "secondary suspended river" treatment of Lujitan in the lower Yellow River. Yellow River 2019, 41, 26-28.

3. Babu, V.; Mullick, A.; Jain, K.; Singh, P. Strength and durability characteristics of high-strength concrete with recycled aggregate-influence of processing. J. Sustain. Cem. Based Mater. 2014, 3, 88-110. [CrossRef] 
4. Silva, R.V.; Brito, J.; Dhir, R.K. Properties and composition of recycled aggregates from construction and demolition waste suitable for concrete production. Constr. Build. Mater. 2014, 65, 201-217. [CrossRef]

5. Ravindrarajah, R.S.; Tam, C.T. Recycling concrete as fine aggregate in concrete. Int. J. Cem. Compos. Lightweight Concr. 1987, 9, 235-241. [CrossRef]

6. Silva, R.V.; Brito, J.; Dhir, R.K. Establishing a relationship between modulus of elasticity and compressive strength of recycled aggregate concrete. J. Clean. Prod. 2016, 112, 2171-2186. [CrossRef]

7. Guo, H.; Shi, C.; Guan, X.; Zhu, J.; Ding, Y.; Ling, T.C.; Zhang, H.; Wang, Y. Durability of recycled aggregate concrete-A review. Cem. Concr. Compos. 2018, 89, 251-259. [CrossRef]

8. Wang, Y.; Zhang, H.; Geng, Y.; Wang, Q.; Zhang, S. Prediction of the elastic modulus and the splitting tensile strength of concrete incorporating both fifine and coarse recycled aggregate. Constr. Build. Mater. 2019, 215, 332-346. [CrossRef]

9. Lu, B.; Shi, C.; Cao, Z.; Guo, M.; Zheng, J. Effect of carbonated coarse recycled concrete aggregate on the properties and microstructure of recycled concrete. J. Clean. Prod. 2019, 233, 421-428. [CrossRef]

10. Carro-López, D.; González-Fonteboa, B.; Brito, J.; Martínez-Abella, F.; González-Taboada, I.; Silva, P. Study of the rheology of self-compacting concrete with fine recycled concrete aggregates. Constr. Build. Mater. 2015, 96, 491-501. [CrossRef]

11. Khatib, J.M. Properties of concrete incorporating fine recycled aggregate. Cem. Concr. Res. 2005, 35, 763-769. [CrossRef]

12. Pereira, P.; Evangelista, L.; Brito, J. The effect of superplasticizers on the mechanical performance of concrete made with fine recycled concrete aggregates. Cem. Concr. Comp. 2012, 34, 1044-1052. [CrossRef]

13. Sičáková, A.; Špak, M. The effect of a high amount of micro-fillers on the long-term properties of concrete. Materials 2019, 12, 3421. [CrossRef] [PubMed]

14. Bravo, M.; Brito, J.; Pontes, J.; Evangelista, L. Mechanical performance of concrete made with aggregates from construction and demolition waste recycling plants. J. Clean. Prod. 2015, 99, 59-74. [CrossRef]

15. Nam, J.; Kim, G.; Yoo, J.; Choe, G.; Kim, H.; Choi, H.; Kim, Y. Effectiveness of fiber reinforcement on the mechanical properties and shrinkage cracking of recycled fine aggregate concrete. Materials 2016, 9, 131. [CrossRef]

16. Xiao, J.; Li, J.; Zhang, C. On statistical characteristics of the compressive strength of recycled aggregate concrete. Struct. Concr. 2005, 6, 149-153. [CrossRef]

17. Kim, Y.; Hanif, A.; Kazmi, S.M.S.; Munir, M.J.; Park, C. Properties enhancement of recycled aggregate concrete through pretreatment of coarse aggregates-comparative assessment of assorted techniques. J. Clean. Prod. 2018, 191, 339-349. [CrossRef]

18. Shi, C.; Li, Y.; Zhang, J.; Li, W.; Chong, L.; Xie, Z. Performance enhancement of recycled concrete aggregate-A review. J. Clean. Prod. 2016, 112, 46-72. [CrossRef]

19. Bostanci, S.C.; Limbachiya, M.; Kew, H. Use of recycled aggregates for low carbon and cost effective concrete construction. J. Clean. Prod. 2018, 189, 176-196. [CrossRef]

20. Haitao, Y.; Shizhu, T. Preparation and properties of high-strength recycled concrete in cold areas. Mater. Constr. 2015, 65, 1-6. [CrossRef]

21. Yildirim, S.T.; Meyer, C.; Herfellner, S. Effects of internal curing on the strength, drying shrinkage and freeze-thaw resistance of concrete containing recycled concrete aggregates. Constr. Build. Mater. 2015, 91, 288-296. [CrossRef]

22. Yue, G.B.; Li, Q.Y.; Gao, S. Influence of quality and replacement rate of recycled fine aggregate on antifreeze performance of concrete. J. Nat. Disasters 2015, 24, 223-228.

23. Chen, D.Y.; Liu, L.B.; Yan, Y.; Tan, K.F.; Liu, H. Effect of different factors on frost resistance of recycled aggregate concrete. J. Wuhan Univ. Technol. 2011, 33, 54-58.

24. Wu, J.; Jing, X.H.; Wang, Z. Uni-axial compressive stress-strain relation of recycled coarse aggregate concrete after freezing and thawing cycles. Constr. Build. Mater. 2017, 134, 210-219. [CrossRef]

25. Salem, R.M.; Burdette, E.G.; Jackson, N.M. Resistance to freezing and thawing of recycled aggregates concrete. ACI Mater. J. 2003, 100, 216-221.

26. Lei, B.; Xiao, J.Z. Research on carbonation resistance of recycled aggregate concrete. J. Build. Mater. 2008, 11, $605-611$.

27. Silva, R.V.; Neves, R.; Brito, J.; Dhir, R.K. Carbonation behaviour of recycled aggregate concrete. Cem. Concr. Compos. 2015, 62, 22-32. [CrossRef] 
28. Liu, S.H.; Yan, P.Y. Properties and microstructure of high performance recycled aggregate concrete. J. Chin. Ceram. Soc. 2007, 35, 456-460.

29. Thomas, C.; Setién, J.; Polanco, J.A. Structural recycled aggregate concrete made with precast wastes. Constr. Build. Mater. 2016, 114, 536-546. [CrossRef]

30. Brito, J.; Ferreira, J.; Pacheco, J.; Soares, D.; Guerreiro, M. Structural, material, mechanical and durability properties and behaviour of recycled aggregates concrete. J. Build. Eng. 2016, 6, 1-16. [CrossRef]

31. Bravo, M.; Brito, J.; Pontes, J.; Evangelista, L. Durability performance of concrete with recycled aggregates from construction and demolition waste plants. Constr. Build. Mater. 2015, 77, 357-369. [CrossRef]

32. Faella, C.; Lima, C.; Martinelli, E.; Pepe, M.; Realfonzo, R. Mechanical and durability performance of sustainable structural concretes: An experimental study. Cem. Concr. Compos. 2016, 71, 85-96. [CrossRef]

33. Nobuaki, O.; Shin-Ichi, M.; Wanchai, Y. Influence of recycled aggregate on interfacial transition zone, strength, chloride penetration and carbonation of concrete. J. Mater. Civ. Eng. 2003, 15, 443-451.

34. Vázquez, E.; Barra, M.; Aponte, D.; Jiménez, C.; Valls, S. Improvement of the durability of concrete with recycled aggregates in chloride exposed environment. Constr. Build. Mater. 2014, 67, 61-67. [CrossRef]

35. Chang, H. Chloride binding capacity of pastes influenced by carbonation under three conditions. Cem. Concr. Compos. 2017, 84, 1-9. [CrossRef]

36. Chang, H.; Feng, P.; Lyu, K.; Liu, J. A novel method for assessing C-S-H chloride adsorption in cement pastes. Constr. Build. Mater. 2019, 225, 324-331. [CrossRef]

37. Zhang, W.; Wang, S.; Zhao, P.; Lu, L.; Cheng, X. Effect of the optimized triple mixing method on the ITZ microstructure and performance of recycled aggregate concrete. Constr. Build. Mater. 2019, 203, 601-607. [CrossRef]

38. Khedmati, M.; Kim, Y.R.; Turner, J.A. Investigation of the interphase between recycled aggregates and cementitious binding materials using integrated microstructural-nanomechanical-chemical characterization. Compos. Part B Eng. 2019, 158, 218-229. [CrossRef]

39. Li, W. Application Research of Recycled Concrete and Recycled Blocks in Green Buildings. Energy Conserv. 2019, 5, 16-17.

40. Liu, C. Study on Mechanical Properties of Recycled Concrete Based on Pavement Tensile Strength. Sichuan Build. Mater. 2019, 45, 1-3.

41. Standard for Test Method of Mechanical Properties on Ordinary Concrete (GB/T 50081-2002); Ministry of Construction of the People's Republic of China: Beijing, China, 2003; pp. 53-67.

42. Technical Code on the Application of Recycled Aggregate Concrete (DG/TJ 08-2018-2007); Shanghai Construction and Transportation Commission: Shanghai, China, 2007; pp. 81-94.

43. Standard for Test Methods of Long-Term Performance and Durability of Ordinary Concrete (GB/T 50082-2009); China Building Industry Press: Beijing, China, 2010; pp. 184-197.

44. Lee, G.C.; Choi, H.B. Study on interfacial transition zone properties of recycled aggregate by micro-hardness test. Constr. Build. Mater. 2013, 40, 455-460. [CrossRef]

45. Liu, Q. Effect of Recycled Aggregate Treatment on Concrete Performance under Freezing and Thawing Cycle. J. Shandong Agric. Univ. 2019, 50, 1-5.

46. Tang, B.; Wang, L.; Zong, L.; Chen, L.; Zhang, C. Experimental study on frost resistance of recycled brick aggregate recycled concrete. Jiangsu Build. Mater. 2015, 3, 26-29.

47. Shu, Q.; Jiang, X.; Dong, Y. Experimental study on durability of brick-rich recycled aggregate concrete. J. Hebei Univ. Eng. 2017, 34, 43-47.

(C) 2019 by the authors. Licensee MDPI, Basel, Switzerland. This article is an open access article distributed under the terms and conditions of the Creative Commons Attribution (CC BY) license (http://creativecommons.org/licenses/by/4.0/). 